ANTIMICROBIAL EFFICACY OF PASSION FRUIT EXTRACT AGAINST ENTEROCOCCUS FAECALIS - AN IN VITRO STUDY

\section{Dental Science}

K Gayathri*

Prathima G.S

R Sajeev

\section{A Sanguida}

Postgraduate Department of Paedodontics and Preventive Dentistry Indira Gandhi Institute of Dental Sciences Pondicherry. *Corresponding Author

Head of the Department Department of Paedodontics and Preventive Dentistry Indira Gandhi Institute of Dental Sciences Pondicherry

Ex Professor Department of Paedodontics and Preventive Dentistry Indira Gandhi Institute of Dental Sciences Pondicherry

Reader Department of Paedodontics and Preventive Dentistry Indira Gandhi Institute of Dental Sciences Pondicherry

\title{
ABSTRACT
}

PURPOSE: Elimination of infectious microorganisms that cause pulpal and periapical diseases through biomechanical preparation and irrigation is mandatory for the success of endodontic therapy. Although many irrigants were used before, a novel approach in the field of endodontics began with the advent of herbal extracts. Passion fruit is an exotic climber possessing many antimicrobial, antifungal and antioxidant properties that fulfil some desirable properties required for an ideal root canal irrigant. Considering these, the study was aimed to compare and assess the antimicrobial efficacy of different concentrations of Passion fruit extract with saline and $\mathrm{NaOCl}$ against E. Faecalis. METHODS: 80 single rooted premolars following the inclusion and exclusion criteria were taken for the study and was divided randomly in to four groups namely Group A- $30 \%$ Passion fruit extract, Group B- 20\% Passion fruit extract, Group C- 0.9\% Normal saline, Group D- 5.25\% Sodium hypochlorite. Before and after irrigation CFU were calculated after canal preparation and irrigation with test and control irrigants was done. All the groups were compared and the data's were analysed statistically. RESULTS: Group A 30\% Passion fruit extract showed a comparable result with Group D- 5.25\% Sodium hypochlorite and was statistically significant CONCLUSION: $20 \%$ and 30\% Passion fruit extract was found effective in reducing the bacterial load and $30 \%$ Passion fruit extract was comparable with $5.25 \%$ Sodium hypochlorite

\section{KEYWORDS}

E. Faecalis, Passiflora, Root Canal Irrigant, Sodium Hypochlorite, Saline

\section{INTRODUCTION}

Microorganisms play a vital role in the progress of pulpal and periapical diseases. Chances for re infections are more for periapical infections and treatment is aimed at preventing them. ${ }^{[1]}$ Enterococcus faecalis is gram positive coccus which can form a biofilm that helps it to resist destruction by phagocytosis, antibodies, and antimicrobials. Amid the procedures in the endodontic treatment, instrumentation and irrigation are vital steps in reducing the microbial load in the root canal system. ${ }^{[2]}$ The complex nature of the root canal hinders the mechanical action during instrumentation and so it is recommended to use irrigant which possess antimicrobial activity, dissolve organic tissue, have lubricant property and have low cytotoxicity as an adjunct. ${ }^{[3]}$

Several antimicrobial solutions are used in endodontic treatment, including Sodium hypochlorite $(\mathrm{NaOCl})$, Chlorhexidine Gluconate (CHX) etc. However, its own disadvantages of unpleasant taste, inability to remove smear layer, short shelf life, short duration of action, and toxic effects on periapical tissues have limited its use against organisms. ${ }^{[4]}$

Recently herbal and plant extracts are being assessed for their efficiency as an irrigant in disinfecting root canals. Studies shows a significant reduction of bacterial load with the antibacterial activity of Mangifera Indica, Ocimum sanctum, Neem leaf extract etc. Passion fruit (Passiflora edulis) is a creeper, and its extract has a wide range of antibacterial, antifungal, anticarcinogenic, potent anti-inflammatory and antioxidant properties. The different constituents of the passion fruit extracts include flavonoids, alkaloids, cyanogenic compounds, glycosides, vitamins, minerals, and terpenoid compounds. The "Passicol" content which is obtained from Passiflora species has antimicrobial activity on extensive array of microbes including Grampositive and Gram-negative bacteria, fungal molds, yeast, and actinomycetes. ${ }^{[5,6]}$ It is nontoxic, possesses better taste and aroma over other irrigants and has the ability to remove smear layer. They hence fulfil some beneficial properties necessary for an ideal root canal irrigant. ${ }^{[7]}$ Considering these properties the study was aimed to compare and analyse the antimicrobial efficacy of different concentrations of Passion fruit extract with saline and $\mathrm{NaOCl}$ against Enterococcus Faecalis.

MATERIALS AND METHODOLOGY

The study was conducted following the institutional review board and ethical clearance. Armamentarium needed for the study is as shown in (figure 1). As per the inclusion and exclusion criteria, 80 extracted teeth were selected for the study. The inclusion criteria include 1 . Lower first premolar extracted for orthodontic treatment 2. Single canal tooth with canal curvature at a range of $0-10^{\circ} 3$. Tooth without any fracture, anomalies 4 . Teeth with no history of root canal treatment. And the exclusion criterion includes 1. Tooth with morphological defect 2. Root resorption 3. Tooth with root fracture 4 . Tooth with calcified canal 5 . Tooth with immature apices

For the preparation of passion fruit extract, $1500 \mathrm{~g}$ of the passion fruit pulp was taken and ground in a mixer, and $1500 \mathrm{~mL}$ of rectified spirit was added to the pulp juice and mixed. This was kept for $24 \mathrm{~h}$ with intermittent stirring in a magnetic stirrer. This mixture was filtered using a muslin cloth. The filtrates were then collected in china dishes, weighed, and stored in desiccators. To prepare $20 \mathrm{~g} \%$ of the alcohol extract, it was taken under sterile conditions and dissolved in $2 \mathrm{~mL}$ of ethyl alcohol and $3 \mathrm{~mL}$ of distilled water.

The teeth were randomly allocated to Group A $-30 \%$ Passion fruit extract, Group B- 20\% Passion fruit extract, Group C- $0.9 \%$ Normal saline Group D- 5.25\% Sodium hypochlorite. Sample size was estimated to be 20 samples per group

\section{PROCEDURE:}

Teeth were selected following the inclusion and exclusion criteria. Decoronation of tooth was done and root length was standardized at 14 $\mathrm{mm}$. Working length was determined using radiographic method and was established $1 \mathrm{~mm}$ short of the radiographic apex. Canal enlargement was done till 50 size using $\mathrm{K}$ file. Canal was irrigated with $17 \%$ EDTA and $5.25 \%$ sodium hypochlorite .To prevent bacterial leakage, the enlarged apical foramina were sealed with epoxy resin and those were mounted vertically in a plaster block .Randomized sampling of tooth for each group was done by lottery method. Tooth was sterilized in an autoclave for 30 minutes at $121^{\circ} \mathrm{C}$.Root canal was filled with brain heart infusion broth . Tooth was infected by keeping it in $\mathrm{BHI}$ broth containing E.faecalis for $24 \mathrm{hrs}$ at $37^{\circ} \mathrm{C}$. Bacterial sample were taken from tooth using endodontic paper points and inoculated in blood agar medium and the numbers of colonies were counted

Irrigation of the root canal with $2 \mathrm{ml}$ of $20 \%$ alcoholic extract of passion fruit for 10 minutes followed by $1 \mathrm{ml}$ of sterile saline solution 
was done using 30-gauge side vent needle which is kept $3 \mathrm{~mm}$ short of the apex. Collection of the bacterial sample was done immediately after irrigation by keeping the sterile paper points in wet canal for 1 minute (same procedure was done with $30 \%$ passion fruit pulp extract and both the control groups .Turbidity check was done using Muller Hilton broth and the samples were inoculated in Blood agar plate and the colony forming units were count. Colony forming units were calculated before irrigation and after irrigation with all the groups (Figure 2, 3, 4, 5). Tabulated values were analysed statistically using Wilcoxon Signed Ranks Test, Kruskal-Wallis Annova Test, and MannWhitney Test

\section{FIGURE 1: ARMAMENTARIUM USED IN THE STUDY}

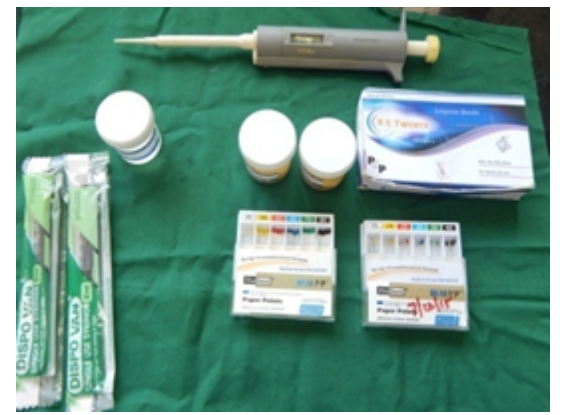

FIGURE 2,3,4,5: Before and after irrigation colonies in blood agar plate

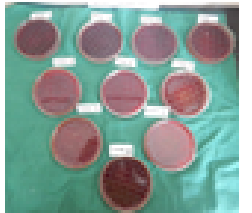

Before

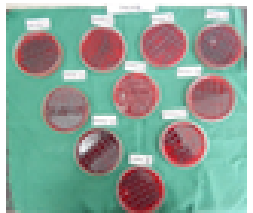

After

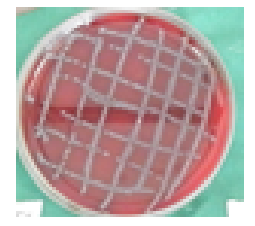

irrigation

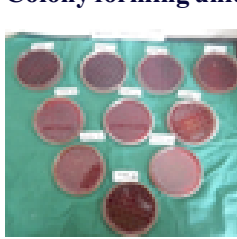

Before

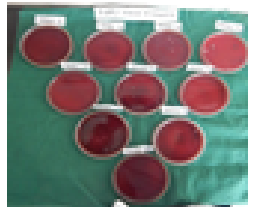

After

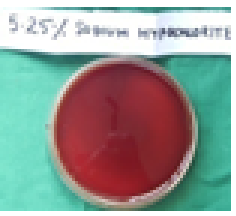

Colony forming units before and after sodium hypochlorite irrigation

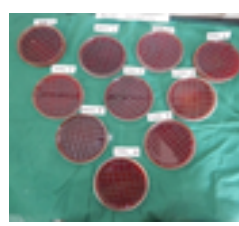

Before

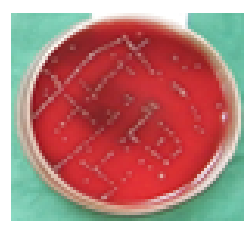

After

Colony forming units before and after $20 \%$ Passion fruit extract irrigation

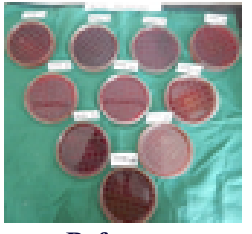

Before

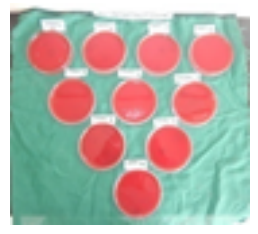

After

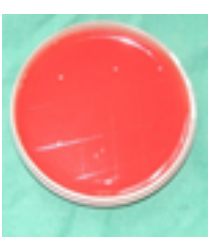

Colony forming units before and after $30 \%$ Passion fruit extract irrigation

\section{RESULTS}

80 extracted premolars were to evaluate the antimicrobial efficacy of passion fruit extract against Enterococcus faecalis bacteria. Four groups were taken in this study with the positive control being $5.25 \%$ sodium hypochlorite and negative control being $0.9 \%$ saline and $20 \%$ and $30 \%$ passion fruit extract as test samples. The bacterial count following before and after irrigation of test samples and control group were calculated in colony forming units

Table 1: Wilcoxon Signed Ranks Test (between GROUP A, B, C, D).

Group A

\begin{tabular}{|c|c|c|c|c|c|}
\hline Groups & $\mathrm{N}$ & $\begin{array}{c}\text { Mean } \\
\text { Rank }\end{array}$ & $\begin{array}{c}\text { Sum of } \\
\text { rank }\end{array}$ & $\mathrm{Z}$ & $\mathrm{P}$ \\
\cline { 1 - 4 } Before Irrigation PFE & 20 & 10.50 & 210.00 & $-4.175 \mathrm{a}$ & .000 \\
\cline { 1 - 4 } After irrigation PFE & 0 & .00 & .00 & & \\
\hline
\end{tabular}

Group B

\begin{tabular}{|c|c|c|c|c|c|}
\hline Groups & $\mathrm{N}$ & $\begin{array}{l}\text { Mean } \\
\text { Rank }\end{array}$ & $\begin{array}{l}\text { Sum of } \\
\text { rank }\end{array}$ & \multirow{3}{*}{$-3.948 a$} & \multirow{3}{*}{.000} \\
\hline Before Irrigation PFE & 20 & 10.50 & 210.00 & & \\
\hline After irrigation PFE & 0 & .00 & .00 & & \\
\hline \multicolumn{6}{|c|}{ Group C } \\
\hline Groups & $\mathrm{N}$ & $\begin{array}{l}\text { Mean } \\
\text { Rank }\end{array}$ & $\begin{array}{l}\text { Sum of } \\
\text { rank }\end{array}$ & $\mathrm{Z}$ & $\mathrm{P}$ \\
\hline Before Irrigation PFE & $9 a$ & 5.00 & 45.00 & \multirow[t]{2}{*}{$-2.810 \mathrm{a}$} & \multirow[t]{2}{*}{.005} \\
\hline After irrigation PFE & $0 \mathrm{~b}$ & .00 & .00 & & \\
\hline \multicolumn{6}{|c|}{ Group D } \\
\hline Groups & $\mathrm{N}$ & $\begin{array}{l}\text { Mean } \\
\text { Rank }\end{array}$ & $\begin{array}{l}\text { Sum of } \\
\text { rank }\end{array}$ & $\mathrm{Z}$ & $\mathrm{P}$ \\
\hline Before Irrigation PFE & $20 \mathrm{a}$ & 10.50 & 210.00 & \multirow[b]{2}{*}{$-4.472 \mathrm{a}$} & \multirow[b]{2}{*}{.000} \\
\hline After irrigation PFE & $0 \mathrm{~b}$ & .00 & .00 & & \\
\hline
\end{tabular}

This indicates a difference in activity by all four irrigants against E.faecalis

Wilcoxon Signed Ranks Test was done to compare the number of colonies before and after irrigation in all the four groups and a statistically significant results with p value as 0.00 was obtained. This indicates a diminution in the number of Enterococcus Faecalis with the use of both test and control irrigants. (Table 1)

\section{Table 2: Kruskal-Wallis Test}

\begin{tabular}{|l|l|l|l|l|l|}
\hline Group & $\mathrm{N}$ & Mean rank & Chi-square & Degree of freedom & $\mathrm{P}$ \\
\hline $30 \% \mathrm{PF}$ & 20 & 58.50 & 74.014 & \multirow{2}{*}{3} & \\
\cline { 1 - 3 } $20 \% \mathrm{PF}$ & 20 & 30.50 & & & \\
\cline { 1 - 2 } & 20 & 10.50 & & & \\
\cline { 1 - 2 } $\mathrm{NaOC}$ & 20 & 62.50 & & & \\
\hline
\end{tabular}

* A P value of 0.00 was obtained from table 2 which shows a higher degree of significance. This indicates a difference in activity by all four irrigants against E.faecalis

When Kruskal-Wallis Annova Test was applied to determine the significance between the four irrigants against Enterococcus faecalis, a $P$ value of 0.00 was obtained This indicates a difference in activity by all four irrigants against Enterococcus faecalis. (Table 2)

\section{Table 3: Mann-Whitney Test Between group A and D}

\begin{tabular}{|l|l|l|l|l|l|}
\hline Groups & $\mathrm{N}$ & Mean Rank & Sum of rank & $\mathrm{Z}$ & $\mathrm{P}$ \\
\cline { 1 - 4 } 30\% & 20 & 18.50 & 370.00 & -2.078 & .038 \\
\cline { 1 - 4 } Sodium hypochlorite & 20 & 22.50 & 450.00 & & \\
\hline
\end{tabular}

*More significant results were obtained between group A and D proving that $\mathrm{NaOCl}$ is a potent irrigant than other groups

Intergroup comparison was done using Mann-Whitney Test and a significant result was obtained in all four groups. Further, more significant results were obtained between group A and D. These results indicate that $\mathrm{NaOCl}$ is a potent irrigant than other groups. (Table 3)

\section{DISCUSSION}

The effectiveness in the cleaning of root canal depends not only on the mechanical action of instruments, but also on the lubricating action of irrigating solutions, its ability in removing smear layer, germicidal potential and its solvent action on exudates. Enterococcus faecalis has been recognized as the organism that is seen in persistent root canal failures. ${ }^{[8]}$ It passively maintains $\mathrm{pH}$ homeostasis by pumping protons into the cell and lowers the internal $\mathrm{pH}$. So, in untreated root canals if present in minute fraction, can cause root canal infection. These 
organisms, if remained within the root canal along with the necessary environment can proliferate and cause reinfection. ${ }^{[9]}$ Limitations of conventional irrigants such as unpleasant taste, inability to remove smear layer, toxic effect on periapical tissues etc have warranted research on herbal products as irrigants .Passion fruit is an exotic climber which is rich in antioxidants and possesses antimicrobial properties because of the presence of its different constituents. So, the present Invitro study was aimed to assess the antibacterial efficacy of passion fruit extract against Enterococcus faecalis.

In the present study, single rooted lower first premolar with single canal that has been extracted for the purpose of orthodontic needs was selected. This is attributed to the fact that single canal help in ease of irrigation as it provides a single path of file placement. Several studies on evaluating the efficacy of irrigants against Enterococcus faecalis have used single rooted premolars. In our study standardization of the root curvature was also done as $0-10^{\circ}$ according to Schneider method to avoid procedural errors, excessive removal of tooth structure and succeeding treatment failure. ${ }^{[10,11]}$

After the tooth was selected following inclusion and exclusion criteria and the standardization of the tooth was met, preparation of the root canal was done. During preparation, irrigation of Canal was performed with $17 \%$ EDTA and $5.25 \%$ Sodium hypochlorite as Sodium hypochlorite removes dentinal remnants and EDTA removes the smear layer. The enlarged apical foramina were then sealed with epoxy resin and were mounted vertically in a plaster block for easier handling and to prevent bacterial leakage. Randomized sampling of tooth was done by lottery method and the teeth were sterilized in an autoclave for 20 minutes at $121^{\circ} \mathrm{C}$. Media used for inoculation and growth of Enterococcus faecalis was Brain Heart Infusion broth as BHI Broth is a nutritious, buffered culture medium that contains infusions of brain and heart tissue of goat and peptones to supply protein and other nutrients necessary to maintain the growth of Enterococcus faecalis. Standard laboratory growing conditions for Enterococcus faecalis is brain heart infusion broth at $35-37^{\circ} \mathrm{C}$ without aeration. The bacterium was inoculated in the broth using an inoculating loop of size $10 \mu 1$.

Studies have proven that natural extracts have potent antibacterial efficacy and hence they can have therapeutic use in endodontics. So far, the major advantages which highlight the promising role of herbs as root canal irrigants includes safety, ease of availability, increased shelf life, its cost effectiveness and lack of bacterial resistance. ${ }^{[12]}$

Passion fruit also known as Passiflora edulis is a climber which belongs to the family Passifloraceae. Traditionally, the flower of passiflora was used for treating ailments. The different constituents of the Passiflora plant products include alkaloids, phenols, glycosides flavonoids, cyanogenic compounds. Study by Birner and nicolis have shown that a content called Passicol obtained from p.edulis is responsible for antibacterial and antifungal properties. ${ }^{[13]}$

Study done by Varghese et al to find out the Antimicrobial activity of pineapple and passion fruit juices have found that the inhibition zone of yellow passion fruit was more than purple passion fruit. $\left[{ }^{[4]}\right.$ Passion fruit was found to be nontoxic and has the ability to remove smear layers. There are matrix metalloproteinase's (MMPs) like MMP-8, MMP-2, MMP-9 present in saliva, pulp or dentine. These MMPs causes destruction of collagen and organic matrix in the hybrid layer and thus contribute in the development of dental caries. So inhibition of MMPS should be done. Fruit extract of passion fruit is known to inhibit these MMP-2 and MMP-9. Hence passion fruit extract if used as an irrigant can inhibit the MMPs thus aiding in improved bonding between dentin and obturating material. ${ }^{[7]}$

Studies conducted by Jayahari et al have concluded that passion fruit extracts were sensitive to Enterococcus faecalis bacteria. ${ }^{[7]}$ In accordance with the study done by Vinay Kumar G et al, the contact time for $2 \mathrm{ml}$ of irrigants was taken as 10 minutes followed by $1 \mathrm{ml}$ of sterile saline and similar study by vijayakumar $\mathrm{S}$ et al used $5 \mathrm{ml}$ of the tested irrigant for a contact time of 5 minutes. ${ }^{[15,16]}$

Results of this study showed that $100 \%$ inhibition of bacterial is shown by $5.25 \%$ sodium hypochlorite and a similar result was seen by $30 \%$ passion fruit extract because of the presence of passicola and other components In accordance with the study done by Siqueira JF et al and Paudel KR et al, normal saline at $0.9 \%$ concentration was used as a negative control. Saline does not possess any antimicrobial properties.
In this study there was slight reduction in bacterial colony forming units when normal saline was used which could be attributed to the mechanical flushing of the bacteria by irrigants ${ }^{[17,18]}$ From this study it could be concluded that natural irrigants like $20 \%$ and $30 \%$ passionfruit extracts show reduction in bacterial load and hence could be used as a substitute for sodium hypochlorite

\section{CONCLUSION}

Within the limitations of this study, 20\% and 30\% Passion fruit extract was found effective in reducing the bacterial load and 30\% Passion fruit extract was comparable with 5.25\% Sodium hypochlorite, hence has the potential of an effective irrigant in the field of paediatric endodontics. Further Invitro and clinical trials are needed to assess the safety and biocompatibility of Passion fruit extracts before conclusively recommending it as an effective intracanal irrigant. Further studies need to be done to evaluate the ability of passion fruit extract in smear layer removal.

\section{REFERENCES}

1. Lotfi M, Vosoughhosseini S, Ranjkesh B, Khani S. Antimicrobial efficacy of nanosilver,sodium hypochlorite and chlorhexidine gluconate against Enterococcus faecalis. Afr J Biotechnol 2011;10(35):6799-6803

2. Dunavant TR, Regan JD, Dentsc B. Comparative Evaluation of Endodontic Irrigants against Enterococcus faecalis Biofilms. J Endod 2006;32(6):527-31

3. Berber VB, Gomes BPFA, Sena NT, Vianna ME, Ferraz CCR, Zaia AA. Efficacy of various concentrations of $\mathrm{NaOCl}$ and instrumentation techniques in reducing Enterococcus faecalis within root canals and dentinal tubules. Int Endod J 2006;39(1):10-17

4. Kaur R, Singh R, Sethi K, Garg S, Miglani S. Irrigating Solutions in Pediatric Dentistry: Literature Review and Update. J Adv Med Dent Scie 2014;2(2):104-115.

5. Patel SS. Morphology and pharmacology of Passiflora edulis - a review. J Herb Med Toxicol 2009; 3(1): 1-6.

6. Zibadi S, Watson RR. Passion fruit (Passiflora edulis) composition, efficacy and safety. Evid Based Integrative Med 2004; 1(1): 183-7

7. Jayahari N,Niranjan N,Kanaparthy A. The efficacy of passion fruit juice as an endodontic irrigant compared with sodium hypochlorite solution:an invitro study. J endodontic irrigant compared with
Investig Clin Dent 2013;4(1):1-7.

8. Sedgley CM, Lennan SL, Appelbe OK. Survival of Enterococcus faecalis in root canal ex vivo. Int Endod J 2005;38: 735-42.

9. Ferraz CC, Figueiredo de Almeida Gomes Bp, Zaia AA, Teixeira FB, de Souza-Filho FJ. In vitro assessment of the antimicrobial action and the mechanical ability of chlorhexidine gel as an endodontic irrigant. J Endod 2001;27(7):452-55

10. Balani P, Niazi F, Rashid H. A brief review of the method used to determine the curvature of root canal. J Rest Dent 2015;3(3):57-63.

11. Schneider SW. A comparison of canal preparations in straight and curved rootcanals Oral Surg Oral Med Oral Pathol. 1971;32:271-5.

12. Jain P, Ranjan M. Role of herbs in root canal irrigation-A review. J Pharm Bioall. Sci 2014;9(2):6-10

13. Birner J and Nicolls M, "Passicol, an antibacterial and antifungal agent produced by Passiflora plant species: preparation and physicochemical characteristics". Antimicrobial Agents and Chemotherapy 1973;3(1):105-109.

14. Varghese N, Anjana R, Joy PP.2015, January Antimicrobial Activity of Pineapple and Passion Fruit Juices. 27th Kerala Science Congress, Alappuzha. Research Gate

15. Vinay kumar G, Uppin V, Shenoy A. Comparison of antibacterial effects of various root (a)

16. Vijaykumar S, GunaShekhar M, Himagiri S. In vitro effectiveness of different endodontic irrigants on the reduction of Enterococcus faecalis in root canals. J Clin Exp Dent. 2010;2(4):169-72

17. Paudel KR, Jaiswal A, Parajuli U, Bajracharya M. Different pharmacological solutions in intracanal irrigation. Nepal Med Coll J 2011; 13(2): 111-114.

18. Siqueira JF Jr, Machado AG, Silveira RM, Lopes HP, Uzeda M. Evaluation of the effectiveness of sodium hypochlorite used with three irrigation methods in the elimination of Enterococcus faecalis from the root canal, in vitro. Int Endod J. 1997;30(4):279-82 